\title{
Study of the fructose 6-phosphate/fructose 1,6-bi-phosphate cycle in the liver in vivo
}

\author{
Emile VAN SCHAFTINGEN, Louis HUE and Henri-Géry HERS \\ Laboratoire de Chimie Physiologique, Université de Louvain and International Institute of Cellular and \\ Molecular Pathology, U.C.L. 75.39, B-1200 Brussels, Belgium
}

(Received 17 April 1980/Accepted 26 June 1980)

\begin{abstract}
1. The method proposed by Rognstad \& Katz [(1976) Arch. Biochem. Biophys. 177, 337-345] for the determination of the fructose 6-phosphate/fructose 1,6-bisphosphate cycle by the randomization of carbon between C-1 and C- 6 of glucose formed from $\left[1-{ }^{14} \mathrm{C}\right]$ galactose was applied to anaesthetized rats and conscious mice. 2. It was checked that the hydrolysis of fructose 6-phosphate by glucose 6-phosphatase is too weak to invalidate the method. The participation of the Cori cycle in the randomization was negligible within the short experimental period used $(2-4 \mathrm{~min})$. 3 . No detectable randomization of carbon was observed in starved animals, indicating that phosphofructokinase is inactive in this experimental condition. 4. Randomization of carbon was detected as soon as $1 \mathrm{~min}$ after administration of $\left[1{ }^{14} \mathrm{C}\right]$ galactose to fed animals and was maximal at about 3-4 min. It was calculated that on average $15 \%$ of the glucose formed by the liver of fed rats was recycled through the triose phosphates. The extent of cycling was quite variable. Recycling was also observed in starved rats in which glucose had been administered intravenously $10 \mathrm{~min}$ previously. In these animals, recycling was completely inhibited by glucagon. 5 . The main factors that appear to be responsible for the very large changes in recycling observed in various experimental conditions are the concentrations of fructose 1,6-bisphosphate and of fructose 6-phosphate and also the affinity of phosphofructokinase for fructose 6-phosphate. The concentration of nucleotides does not seem to play a role.
\end{abstract}

The simultaneous operation of phosphofructokinase and of hexose bisphosphatase in the liver would allow a so-called futile recycling of metabolites between fructose 6-phosphate and fructose 1,6-bisphosphate. Several methods have been proposed to measure this cycle. Those based on the release of ${ }^{3} \mathrm{H}_{2} \mathrm{O}$ from $\left[3-{ }^{3} \mathrm{H}\right]-$ or $\left[5-{ }^{3} \mathrm{H}\right]$-glucose are subject to criticism or have poor sensitivity (for reviews, see Katz \& Rognstad, 1976; Hue, 1980). Recycling of hexoses to the level of triose phosphates can also be detected by randomization of carbon between the upper and the lower halves of the $\mathrm{C}_{6}$ molecule, as is expected to occur by the combined action of aldolase and triose phosphate isomerase. Rognstad \& Katz (1976) measured the presence of ${ }^{14} \mathrm{C}$ in C-6 of the glucose formed from $\left[1-{ }^{14} \mathrm{C}\right]$ galactose by isolated hepatocytes. They observed an easily detectable randomization of carbon, which they attributed to the fructose 6-phosphate/fructose 1,6-bisphosphate futile cycle (see Scheme 1). This randomization was greatly diminished by glucagon or ethanol.
However, it must be noted that the randomization of carbon is a proper measurement of the futile cycle only if the interconversion of fructose 6-phosphate and triose phosphates does not occur by other mechanisms than the phosphofructokinase/hexose bisphosphatase antagonism. This assumption may, however, not be correct. Indeed, Beaufay \& de Duve (1954) have shown that the activity of glucose 6-phosphatase on fructose 6phosphate could liberate an appreciable amount of free fructose. As shown in Scheme 1, this fructose would in turn be phosphorylated to fructose 1phosphate and from there reach the triose phosphates pool. The Cori cycle is, of course, another mechanism, which in the course of experiments in vivo, would also give rise to an important randomization of carbon atoms. Finally there is also a possibility that transaldolase-catalysed exchange of carbon between triose phosphates and the lower half of fructose 6-phosphate would bypass the action of hexose bisphosphatase. The latter possibility appears unlikely, however, since the distribution of ${ }^{14} \mathrm{C}$ in 


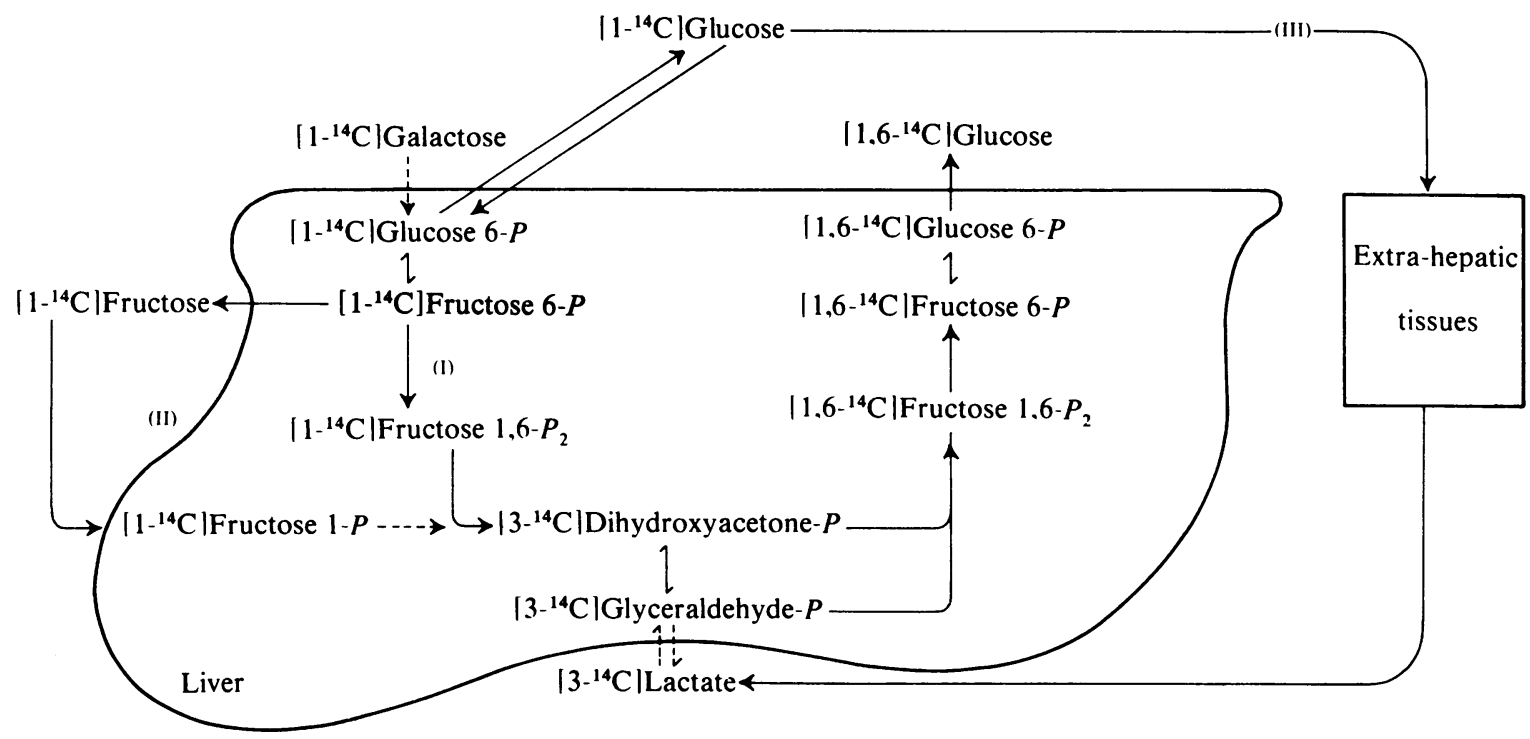

Scheme 1. Mechanism of the randomization of $C-1$ to $C-6$ in glucose after the administration of $\left[1-{ }^{14} C\right]$ galactose or $\left[1-{ }^{14} \mathrm{C}\right] \mathrm{glucose}$

The conversion of hexose 6-phosphates to triose phosphates may occur through: (I) phosphofructokinase and aldolase; (II) glucose 6-phosphatase, fructokinase and aldolase; (III) the Cori cycle,

liver glycogen after administration of $\left[1-{ }^{14} \mathrm{C}\right]-$ fructose to rats indicates that there is more radioactivity in C-1 than in C-6 (Hers, 1955). The transaldolase-catalysed exchange would have resulted in more radioactivity in C-6.

In the present paper, the validity of the method of Rognstad \& Katz (1976) has been reconsidered and the possibility of participation of glucose 6phosphatase in the conversion of fructose 6phosphate into triose phosphates has been ruled out. We have then applied this method to rats and mice in vivo, under conditions in which recycling of metabolites through the Cori cycle was minimized. We have simultaneously analysed the concentration of metabolites in the liver as well as the activity of the two forms of phosphofructokinase described by several groups of workers (Castaño et al., 1979; Kagimoto \& Uyeda, 1979; Pilkis et al., 1979; Nieto $\&$ Castaño, 1980). These authors have indeed found that glucagon causes the appearance of a form of phosphofructokinase which has less affinity for fructose 6-phosphate.

\section{Materials and methods}

\section{Chemicals and enzymes}

Biochemical reagents and purified enzymes were obtained from Boehringer G.m.b.H. (Mannheim, Germany). $\left[1^{-14} \mathrm{C}\right]$ Galactose and $\left[1{ }^{14} \mathrm{C}\right]$ glucose $(50 \mathrm{mCi} / \mathrm{mmol})$ purchased from The Radiochemical
Centre (Amersham, Bucks., U.K.) were purified by chromatography on Whatman 3MM paper respectively in butanol/ethanol/acetic acid/water $(8: 3: 1: 2$, by vol.) and in phenol saturated with water. Sodium pentobarbital was from Serva (Heidelberg, Germany). Glucagon was from Novo Industri (Copenhagen, Denmark). Ion-exchange resin AG1 (X8; 200-400 mesh) was from Bio-Rad Laboratories (Richmond, CA, U.S.A.).

\section{Experiments with intact animals}

The experiments were performed between 10:00 and 16:00 h. Male Wistar rats, fed ad libitum or starved overnight, and weighing $200-300 \mathrm{~g}$ were anaesthetized by intraperitoneal injection of pentobarbital $(6 \mathrm{mg} / 100 \mathrm{~g}$ body wt.). The abdomen was opened $15 \mathrm{~min}$ after the injection of the anaesthetic and a well-stoppered catheter (Longdwel, 16 gauge) filled with heparin ( 5000 units $/ \mathrm{ml}$ ) was inserted into the aorta. A tracer amount of radioactive galactose or glucose $\left(2.5 \times 10^{6}\right.$ c.p.m. $/ 100 \mathrm{~g}$ body wt. in $0.15 \mathrm{M}$ $\mathrm{NaCl})$ was then injected slowly (15 s) into the portal vein and blood samples $(0.7 \mathrm{ml})$ were collected from the aorta at various times thereafter. In experiments in which liver metabolites were measured, a single blood sample $(1 \mathrm{ml})$ was taken from the vena cava 3 min after the injection of the tracer, and the liver was quick-frozen in situ (Wollenberger et al., 1960). When indicated, glucose $(200 \mathrm{mg} / 100 \mathrm{~g}$ body wt.) or glucagon $(0.1 \mathrm{mg} / 100 \mathrm{~g}$ body wt.) was administered 
in the vein of the penis 10 and 2 min respectively before the injection of the radioactive tracer.

For the experiments with conscious mice, radioactive glucose or galactose $\left(2 \times 10^{7}\right.$ c.p.m. $/ 100 \mathrm{~g}$ body wt. in $0.2 \mathrm{ml}$ of $0.15 \mathrm{M}-\mathrm{NaCl}$ ) was injected in the tail vein of male NMRI mice weighing between 20 and $30 \mathrm{~g}$. The animals were killed by decapitation 2 min after the injection; blood was collected on pieces of Parafilm (American Can Co., Greenwich, CT, U.S.A.).

\section{Purification and analysis of radioactive glucose}

Blood samples were mixed with 1 vol. of $0.15 \mathrm{M}$ $\mathrm{Ba}(\mathrm{OH})_{2}$ and 1 vol. of $0.15 \mathrm{M}-\mathrm{ZnSO}_{4}$ (Weichselbaum \& Somogyi, 1941). The mixture was centrifuged and $1 \mathrm{ml}$ of the supernatant was passed through a column $(0.5 \mathrm{~cm} \times 4 \mathrm{~cm})$ of Dowex AG 1 (X8; formate form) to remove labelled anions. The eluate $(4 \mathrm{ml})$ was then heated for $5 \mathrm{~min}$ at $100^{\circ} \mathrm{C}$ to destroy contaminating traces of phosphoglucoisomerase; after cooling, the solution was treated with $5 \mu \mathrm{g}$ of hexokinase and $30 \mu \mathrm{mol}$ of MgATP adjusted to $\mathrm{pH} 7$ with $\mathrm{KOH}$ and the total volume made up to $5 \mathrm{ml}$ with water. This mixture was incubated for $30 \mathrm{~min}$ at $30^{\circ} \mathrm{C}$ and then heated at $100^{\circ} \mathrm{C}$ for $5 \mathrm{~min}$. It was then cooled and passed again through a column $(0.5 \mathrm{~cm} \times 4 \mathrm{~cm})$ of Dowex AG 1 (X8; formate form). The column was washed with $3 \mathrm{ml}$ of water, which removed the radioactive galactose, and with $3 \mathrm{ml}$ of $1 \mathrm{M}-\mathrm{NaCl}$, which eluted glucose 6-phosphate. The latter fraction was incubated for $3 \mathrm{~h}$ at $30^{\circ} \mathrm{C}$ in the presence of $20 \mu \mathrm{g}$ of alkaline phosphatase $/ \mathrm{ml}, 1 \mathrm{~mm}$ $\mathrm{MgCl}_{2}, 0.1 \mathrm{mM}-\mathrm{ZnCl}_{2}$ and $30 \mathrm{~mm}$-borate adjusted to pH 9 with $\mathrm{HCl}$, in a total volume of $3.5 \mathrm{ml}$. A $2 \mathrm{ml}$ portion of this solution was used for periodation of glucose and determination of the radioactivity present in C- 6 by the method of Bloom (1962); $0.5 \mathrm{ml}$ of the same solution was used to measure the total radioactivity. Radioactivity was measured with a liquid-scintillation spectrometer by using Biofluor (New England Nuclear, Dreieichenhain, Germany) as scintillation mixture.

This separation procedure eliminates more than $99.5 \%$ of the lactate present in the $\mathrm{Zn}-\mathrm{Ba}$ extract and more than $99.8 \%$ of the galactose. Commercial preparations of $\left[1^{-14} \mathrm{C}\right]$ glucose and $\left[1-{ }^{14} \mathrm{C}\right]$ galactose contained up to $2 \%$ of radioactivity appearing as formaldehyde after periodate oxidation; after chromatography this value fell to less than $0.02 \%$. The procedure of isolation of glucose by phosphorylation and dephosphorylation brought this value to $0.2 \%$. Results have been corrected accordingly.

\section{Measurement of phosphofructokinase activity}

Frozen liver samples (about 1g) were homogenized in Potter-Elvehjem tubes with $10 \mathrm{vol}$. of an ice-cold solution containing $50 \mathrm{~mm}$-Hepes [4-(2-hydroxyethyl)- 1 - piperazine-ethanesulphonic acid], $100 \mathrm{mM}-\mathrm{KF}$ and $15 \mathrm{mM}$-EGTA adjusted to $\mathrm{pH} 7.4$ with $\mathrm{KOH}$. After centrifugation for $15 \mathrm{~min}$ at $60000 \mathrm{~g}$, the clear supernatants were frozen in solid $\mathrm{CO}_{2}$ in acetone until further processed. The activity was assayed spectrophotometrically at room temperature $\left(20-22^{\circ} \mathrm{C}\right)$ at $\mathrm{pH} 7.1$ with suboptimal $(0.25 \mathrm{mM})$ and saturating $(5 \mathrm{mM})$ concentrations of fructose 6-phosphate in the assay mixture of Castaño et al. (1979). Auxiliary enzymes were desalted on Sephadex G-25. Samples $(50 \mu \mathrm{l})$ of the thawed supernatant were preincubated for $5 \mathrm{~min}$ at room temperature in the presence of all the constituents of the assay except MgATP, which was added to start the reaction. The reaction rate decreased during the first $5 \mathrm{~min}$ and then remained almost constant for another $5 \mathrm{~min}$; this latter rate was taken for the measurement of the activity after correction for controls which were run without fructose 6-phosphate. There was indeed a slight blank value attributable to the activity of NADH oxidase. As previously noted by other authors (Underwood \& Newsholme, 1965; Emerk \& Frieden, 1975), the order of addition of substrate, the $\mathrm{pH}$ and the final dilution of the extract were important factors to obtain reproducible results.

\section{Measurement of metabolites}

Glucose (Huggett \& Nixon, 1957), glucose 6-phosphate and fructose 6-phosphate (Hohorst, 1963), fructose 1,6-bisphosphate and triose phosphates (Bücher \& Hohorst, 1963), ATP (Lamprecht \& Trautschold, 1963), ADP and AMP (Adam, 1963) were measured in neutralized perchlorate extracts by enzymic methods as indicated.

\section{Isolation of microsomal fraction from the liver}

Microsomal fraction was isolated from rat liver by the method of Kamath \& Rubin (1972), then washed five times in $8 \mathrm{mM}-\mathrm{CaCl}_{2}$ and finally resuspended in $0.25 \mathrm{M}$-sucrose. The recovery of glucose 6-phosphatase in the last pellet was $74 \%$, whereas no phosphoglucoisomerase activity could be detected. Glucose 6-phosphatase activity was measured by the release of $P_{i}$ from glucose 6phosphate and fructose 6-phosphate as described by Hers (1964).

\section{Results}

\section{Specificity of glucose 6-phosphatase}

The kinetic parameters for the hydrolysis of glucose 6-phosphate and fructose 6-phosphate were measured with a purified microsomal preparation. Glucose 6-phosphate was hydrolysed with a $V_{\max }$ of $9 \mu \mathrm{mol} / \mathrm{min}$ per $\mathrm{g}$ of liver and a $K_{\mathrm{m}}$ of $2.2 \mathrm{mM}$. Fructose 6-phosphate was hydrolysed with a $V_{\max }$. of only $3 \mu \mathrm{mol} / \mathrm{min}$ per $\mathrm{g}$ of liver, and its $K_{\mathrm{m}}$ value 
(28 mM) was more than 10 times that for glucose 6-phosphate.

\section{Experiments with anaesthetized rats}

As illustrated by Fig. 1, the rate of galactose utilization and glucose formation was approximately the same in fed and starved rats. Galactose was rapidly utilized during the first 2 min after its administration; radioactive glucose was hardly detectable at $30 \mathrm{~s}$ and its concentration increased rapidly during the next $2 \mathrm{~min}$. In contrast, there was a great difference between the two experimental conditions

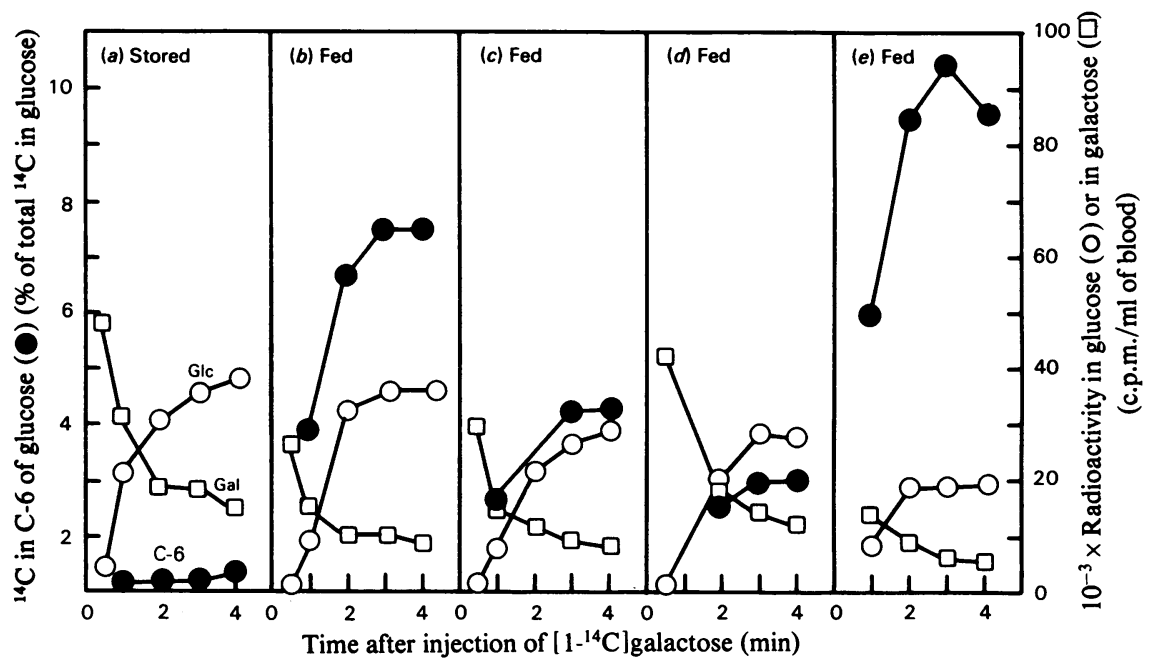

Fig. 1. Time course of the conversion of $\left[1{ }^{-14} \mathrm{C}\right]$ galactose into $\left[1,6-{ }^{14} \mathrm{C}\right]$ glucose in anaesthetized rats Seven experiments of this type were performed with both starved or fed animals. In starved rats, as exemplified in Fig. $1(a)$, nearly no activity was recovered in C-6 of glucose. In fed rats, the randomization was quite variable, and examples of results are shown in Figs. 1(b)-1(e).

Table 1. Radioactivity in $C-6$ of glucose present in blood 3 min after injection of $\left[1-^{14} \mathrm{Clgalactose}\right.$ or $\left[1-{ }^{14} \mathrm{C}\right] \mathrm{glucose}$ to anaesthetized rats

The radioactive precursors were administered in the portal vein and the blood was collected either from the aorta (Expt. 1) or from the vena cava (Expt. 2). Values shown are means \pm S.E.M. for the numbers of observations in parentheses.

Expt. 1

Tracer $\quad \ldots\left[1{ }^{14} \mathrm{C}\right] \mathrm{Galactose}$

${ }^{14} \mathrm{C}$ in C-6

of glucose

(\% of total

Conditions

Fed ${ }^{14} \mathrm{C}$ in glucose)

$4.6 \pm 1.1$

(7)

Fed + glucagon

$5.8,2.7$

Starved

$0.20 \pm 0.03$

Starved + glucagon

(7)

$0.2,0.3$

Starved + glucose

$1.9 \pm 0.4$

(3)

Starved + glucose + glucagon
Expt. 2

\begin{tabular}{|c|c|c|c|c|}
\hline \multirow[b]{2}{*}{$\begin{array}{l}\text { [Glucose] } \\
\text { in blood } \\
(\mu \mathrm{mol} / \mathrm{ml})\end{array}$} & \multicolumn{2}{|c|}{$\left[1-{ }^{14} \mathrm{C}\right]$ Galactose } & \multicolumn{2}{|c|}{$\left[1-{ }^{14} \mathrm{C}\right]$ Glucose } \\
\hline & $\begin{array}{l}10^{-3} \times{ }^{14} \mathrm{C} \\
\text { in glucose } \\
\text { (c.p.m./ml) }\end{array}$ & $\begin{array}{l}{ }^{14} \mathrm{C} \text { in } \mathrm{C}-6 \\
\text { of glucose } \\
\text { (\% of total } \\
{ }^{14} \mathrm{C} \text { in } \\
\text { glucose) }\end{array}$ & $\begin{array}{l}10^{-3} \times{ }^{14} \mathrm{C} \\
\text { in glucose } \\
\text { (c.p.m./ml) }\end{array}$ & $\begin{array}{l}{ }^{14} \mathrm{C} \text { in C-6 } \\
\text { of glucose } \\
\text { (\% of total } \\
{ }^{14} \mathrm{C} \text { in } \\
\text { glucose) }\end{array}$ \\
\hline $\begin{array}{c}4.2 \pm 0.3 \\
(6) \\
6.2 \pm 0.5\end{array}$ & $\begin{array}{c}14.9 \pm 2.2 \\
(3) \\
20.4 \pm 1.2\end{array}$ & $\begin{array}{r}4.9 \pm \\
(3) \\
4.7 \pm\end{array}$ & $\begin{array}{c}49.6 \pm 3.8 \\
(3) \\
52.5 \pm 1.4\end{array}$ & $\begin{array}{c}0.5 \pm 0.3 \\
(3) \\
0.9,0.4\end{array}$ \\
\hline & & & & \\
\hline $\begin{array}{l}3.3 \pm 0 . \\
(10)\end{array}$ & & (0) & $\begin{array}{c}33.2 \pm 4.1 \\
(6)\end{array}$ & \\
\hline $\begin{array}{c}4.2 \pm 0.3 \\
(6)\end{array}$ & $\begin{array}{c}19.9 \pm 1.2 \\
(3)\end{array}$ & $0.20 \pm 0.05$ & $\frac{52.3 \pm 4.4}{(3)}$ & $0.20 \pm 0.04$ \\
\hline $\begin{array}{c}16.2 \pm 0.7 \\
(6)\end{array}$ & $\begin{array}{c}3.1 \pm 0.3 \\
(7)\end{array}$ & $2.6 \pm 0.6$ & $\frac{51.6 \pm 1.3}{(3)}$ & $0.20 \pm 0.06$ \\
\hline$\underset{(6)}{18.1 \pm 0.4}$ & $\underset{(6)}{23.2 \pm 1.7}$ & $\begin{array}{c}0.4 \pm 0.1 \\
(6)\end{array}$ & $48.7 \pm 4.5$ & $0.2 \pm 0.1$ \\
\hline
\end{tabular}


in the amount of the radioactivity recovered in C-6 of the newly formed glucose. This amount was barely detectable in the starved rats (Fig. 1a), whereas in fed animals it increased progressively during the first $3 \mathrm{~min}$ and levelled off at values which, although quite variable, could be as high as $10 \%$ of the total radioactivity of the sugar. These variations were observed in each group of experiments independently of the time of day at which they were performed. Several examples of such experiments are shown in Figs. $1(b)-1(e)$.

On the basis of this time course we have performed blood and liver sampling at $3 \mathrm{~min}$ after the administration of galactose. Table 1 shows that, at that time, the mean value of randomization in blood glucose from fed animals was 20-40-fold greater than that observed in starved animals. The administration of glucose to starved rats $10 \mathrm{~min}$ before the experiment greatly decreased the conversion of galactose into glucose, presumably because it favoured its conversion into glycogen; remarkably, the proportion of radioactivity found in C-6 of the glucose formed was comparable with that observed in fed animals. The administration of glucagon cancelled these two effects of glucose in the starved animals, although it was without action on the randomization of carbon in fed rats. Control experiments performed with $\left[1-{ }^{14} \mathrm{C}\right]$ glucose under similar conditions yielded a higher randomization in fed than in starved rats. The values recorded were smaller than those obtained with $\left[1-{ }^{14} \mathrm{C}\right]$ galactose as a precursor.

Table 2 shows the concentration of several metabolites measured in livers under the various experimental conditions investigated. Starvation was characterized by a remarkably low concentration of fructose 1,6-bisphosphate (one-sixth of the value in the fed animals) and hexose 6-phosphates. The concentration of ATP was decreased, whereas those of ADP and AMP were increased. The administration of glucose to starved rats increased the concentration of all sugar phosphates to the value found under conditions of feeding, but was without influence on the concentration of the nucleotides. In all experimental conditions, glucagon increased the concentration of hexose 6-phosphates, as expected, but decreased that of fructose 1,6-bisphosphate, except in starved animals, in which this concentration was already very low. It also increased the concentrations of ADP and AMP at the expense of ATP.

Table 3 shows the activity of phosphofructokinase, measured at low and high concentrations of fructose 6-phosphate, and the ratio of these two values (activity ratio). This ratio is an index of the

Table 2. Concentrations of metabolites in the livers of anaesthetized rats

Results are for the same biological material as in Expt. 2 of Table 1. Results are expressed per $\mathrm{g}$ wet wt. of liver. Values shown are means \pm S.E.M. for 6 or $12^{*}$ observations.

\begin{tabular}{lcccccc}
\multicolumn{1}{c}{ Conditions } & $\begin{array}{c}\text { [Glucose } \\
\text { 6-phosphate] } \\
(\mathrm{nmol} / \mathrm{g})\end{array}$ & $\begin{array}{c}\text { [Fructose } \\
\text { 6-phosphate] } \\
(\mathrm{nmol} / \mathrm{g})\end{array}$ & $\begin{array}{c}\text { [Fructose } \\
\text { 1,6-bisphosphate] } \\
(\mathrm{nmol} / \mathrm{g})\end{array}$ & $\begin{array}{c}{[\mathrm{ATP}]} \\
(\mu \mathrm{mol} / \mathrm{g})\end{array}$ & $\begin{array}{c}\text { [ADP] } \\
(\mu \mathrm{mol} / \mathrm{g})\end{array}$ & $\begin{array}{c}\text { [AMP] } \\
(\mathrm{nmol} / \mathrm{g})\end{array}$ \\
Fed & $143 \pm 16$ & $46 \pm 4$ & $32 \pm 4$ & $3.42 \pm 0.02$ & $0.93 \pm 0.03$ & $89 \pm 2$ \\
Fed + glucagon & $740 \pm 60$ & $151 \pm 11$ & $16 \pm 3$ & $2.89 \pm 0.11$ & $1.34 \pm 0.07$ & $210 \pm 22$ \\
Starved & $60 \pm 3^{*}$ & $17 \pm 1^{*}$ & $5 \pm 1$ & $3.06 \pm 0.08^{*}$ & $1.08 \pm 0.04^{*}$ & $185 \pm 20^{*}$ \\
Starved + glucagon & $109 \pm 10$ & $20 \pm 2$ & $6 \pm 1$ & $2.66 \pm 0.11$ & $1.43 \pm 0.06$ & $287 \pm 22$ \\
Starved + glucose & $176 \pm 13$ & $43 \pm 1$ & $47 \pm 6$ & $2.91 \pm 0.08$ & $1.05 \pm 0.05$ & $185 \pm 8$ \\
Starved + glucose & $458 \pm 21$ & $90 \pm 9$ & $8 \pm 2$ & $2.47 \pm 0.13$ & $1.47 \pm 0.08$ & $303 \pm 29$ \\
$\quad$
\end{tabular}

Table 3. Activity of phosphofructokinase in livers of anaesthetized rats

Results are for the same biological material as in Expt. 2 of Table 1. Values shown are means \pm S.E.M. for 4 or $8^{*}$ observations.

Activity of phosphofructokinase ( $\mu \mathrm{mol}$ of Fru-1,6- $P_{2}$ formed/min per g wet wt.)

$\begin{array}{lccc} & & & \text { Activity ratio } \\ \text { Fed } & v_{0.25}(0.25 \mathrm{mM}-\text { Fru-6-P) } & V_{\max .}(5 \mathrm{mM}-\mathrm{Fru}-6-P) & v_{0.25} / V_{\max } \\ \text { Fed + glucagon } & 0.66 \pm 0.05 & 1.07 \pm 0.03 & 0.64 \pm 0.04 \\ \text { Starved } & 0.38 \pm 0.04 & 1.01 \pm 0.04 & 0.37 \pm 0.03 \\ \text { Starved + glucagon } & 0.25 \pm 0.03 & 0.78 \pm 0.03 & 0.31 \pm 0.03 \\ \text { Starved + glucose } & 0.13 \pm 0.04 & 0.76 \pm 0.03 & 0.18 \pm 0.03 \\ \text { Starved + glucose } & 0.52 \pm 0.07 & 1.01 \pm 0.05 & 0.51 \pm 0.05 \\ \quad \text { + glucagon } & 0.12 \pm 0.01 & 0.90 \pm 0.05 & 0.13 \pm 0.01 \\ & & & \end{array}$

Vol. 192 
Table 4. Radioactivity in $C-6$ of glucose present in blood 2 min after injection of $\left[1-{ }^{14} \mathrm{C}\right.$ galactose or $\left[1-{ }^{14} \mathrm{Clglucose}\right.$ to conscious mice

All experiments were performed around 12:00h. Values shown are means \pm S.D. for the numbers of observations shown in parentheses.

$\begin{array}{lcccc} & & & \overbrace{\left[1-{ }^{14} \mathrm{C}\right] \text { Galactose }}^{14} \mathrm{C} \text { in } \mathrm{C}-6 \text { of glucose (\% of total }{ }^{14} \mathrm{C} \text { in glucose) } \\ \text { Conditions } & \text { Precursor } & \ldots & {\left[1-{ }^{14} \mathrm{C}\right] \text {-Glucose }} \\ \text { Fed } & & & 2.12 \pm 1.61(18) & 0.35 \pm 0.14(16) \\ \text { Starved } & & & 0.24 \pm 0.08(10) & 0.16 \pm 0.09(10)\end{array}$

state of activation of the enzyme. It was decreased by starvation and by glucagon, and these two effects were additive. Starvation also induced a small but significant decrease in $V_{\max }$. Glucose counteracted the effect of starvation on both $V_{\max }$. and activity ratio.

\section{Experiments with conscious mice}

Since all the experiments described in the preceding section were performed on anaesthetized animals, it was important to check to what extent anaesthesia by itself could be responsible for some of the results observed. For this purpose, conscious mice rather than rats were chosen because of the ease of injection into the tail vein. Table 4 shows that in agreement with the results obtained in rats, there was nearly no randomization of carbon formed from either $\left[1-{ }^{14} \mathrm{C}\right]$ glucose or $\left[1-{ }^{14} \mathrm{C}\right]$ galactose in the starved animals. Under conditions of feeding there was, on average, 10 times more randomization than in the starved animals, although with a very large variation of results. Indeed, in 4 out of 18 animals, the value of randomization was as low as in starved mice. Results with $\left[1-{ }^{14} \mathrm{C}\right]$ glucose indicate that the activity of the Cori cycle could not explain the high values of randomization observed in the majority of fed mice.

\section{Discussion}

\section{Validity of the method}

From the kinetic properties of the microsomal glucose 6-phosphatase previously described by Beaufay \& de Duve (1954), one calculates that the enzyme produces nearly one-tenth as much fructose as glucose from a mixture of hexose phosphates maintained at the equilibrium of phosphoglucoisomerase. Assuming that half of this fructose is reconverted into glucose, and knowing that in the course of this transformation one-third of $\mathrm{C}-1$ atoms are randomized with those at C-6 (Hers, 1955), one would expect to find as much as $1.5 \%$ of the radioactivity in C-6 of the glucose formed from $\left[1{ }^{14} \mathrm{C}\right]$ galactose. This value is about one order of magnitude above what we have actually observed in the starved animal. Therefore we have reinvesti- gated the kinetic properties of glucose 6-phosphatase. We were able to confirm that fructose 6-phosphate can be hydrolysed by this enzyme, but the $K_{\mathrm{m}}$ value $(28 \mathrm{~mm})$ was more than 7 times greater than that reported by Beaufay \& de Duve (1954) $(3.7 \mathrm{~mm})$. This difference is presumably explained by a complete removal of phosphoglucoisomerase from our microsomal preparation, by the five successive sedimentations that we have applied. Indeed, as previously discussed by Beaufay \& de Duve (1954), the presence of a trace amount of isomerase in the microsomal fraction would allow the formation of $P_{1}$ from fructose 6-phosphate by a two-step mechanism which would mimic the direct hydrolysis. From our data, one calculates that the amount of fructose formed by the liver would be about $1 \%$ of the amount of glucose. This amount is too small to invalidate the method.

The participation of the Cori cycle is presumably minimal under our experimental conditions because of the short duration of the experiments. Furthermore, in the anaesthetized rats, the precursor galactose was presented directly to the liver, whereas the labelled glucose formed was later greatly diluted in the whole mass of the body water. The randomization of carbon in control experiments performed with $\left[1-{ }^{14} \mathrm{C}\right]$ glucose as a substrate accounts entirely for the values observed with galactose in the starved animal, with or without glucagon. One can therefore conclude that there was no detectable recycling under these conditions. The higher values observed with $\left[1{ }^{14} \mathrm{C}\right.$ ]glucose in fed animals may be in part explained by some recycling between glucose and triose phosphates in the liver itself.

\section{Recycling in the liver of fed animals}

Randomization of carbon was systematically observed, although to a variable degree, in the glucose formed by anaesthetized fed rats. These results are, however, in contradiction with those obtained by other methods in fed animals (see 'Comparison with other work' below) and could therefore be artefacts, being possibly an effect of anaesthesia. Results obtained with conscious fed mice also revealed an important randomization of carbon at least in about three-quarters of the animals, 
with again a great variability. One therefore concludes that phosphofructokinase is operative in the livers of most, but not all, fed animals.

The maximal randomization observed was close to $10 \%$ and the mean value was about $5 \%$. A quantitative estimation of the fructose 6-phosphate/ fructose 1,6-bisphosphate cycle from these data must take into consideration the incomplete equilibration of triose phosphates revealed by previous work performed with specifically labelled fructose. Indeed, it has been repeatedly found (Hers, 1955; Landau \& Merlevede, 1963; Rauschenbach \& Lamprecht, 1964; Williams \& Landau, 1972) that about one-third of the radioactivity recovered in liver glycogen or glucose formed from $\left[1-{ }^{14} \mathrm{C}\right]$ fructose was in C-6 instead of the $50 \%$ expected if the randomization had been complete. We will thus take as an assumption that $33 \%$ is the maximal randomization that could be obtained after a single passage through the cycle. It therefore appears that, on average, $15 \%$ of the glucose formed by the liver of fed animals has been recycled through the triose phosphates. The maximal value could be close to $30 \%$.

\section{Absence of recycling in the starved animal}

The absence of randomization of carbon in the glucose formed by the starved animal allows one to conclude that there is no recycling between fructose 6-phosphate and fructose 1,6-bisphosphate in this experimental condition. Since gluconeogenesis is an active process in these animals, it appears that glycolysis is not operative and that phosphofructokinase is inactive. The physiological relevance of this observation is obvious in a condition in which gluconeogenesis is essential for survival. The presence of an inactive phosphofructokinase may be explained by a decreased concentration of both fructose 6-phosphate and fructose 1,6-bisphosphate (Table 2) and by a lower affinity of the enzyme for its substrate (Table 3 ).

\section{Effect of glucose}

The near-complete inability of the livers of starved rats to convert fructose 6-phosphate into fructose 1,6-bisphosphate was rapidly reversed by glucose administration. This dramatic effect of glucose can be explained by an increased concentration of the substrate fructose 6-phosphate or of the activator fructose 1,6-bisphosphate (Table 2), or by a stable change in the kinetic properties of phosphofructokinase (Table 3). The last change may result from a secretion of insulin, which is known to antagonize the inactivating action of glucagon on phosphofructokinase (Castaño et al., 1979).

\section{Effect of glucagon}

Glucagon was previously shown to decrease greatly the fructose 6-phosphate/fructose 1,6-bisphosphate cycle in isolated hepatocytes (Rognstad \& Katz, 1976) and to inactivate phosphofructokinase in similar preparations (Castaño et al., 1979; Kagimoto \& Uyeda, 1979; Pilkis et al., 1979). This second effect could therefore explain the first one. However, in vivo, there was a dissociation between these two effects, since the first one was only observed in starved rats in which phosphofructokinase had been re-activated by administration of glucose, but not in fed rats. By contrast, the second effect was observed in both conditions. Other changes, such as an increased concentration of fructose 6-phosphate, a decreased concentration of fructose 1,6-bisphosphate and the conversion of ATP into ADP and AMP, were observed in both fed and starved animals, although to a variable degree. The concentration of hexose phosphates was indeed markedly higher in the liver of fed than of starved animals.

Finally, it must be recalled that the well-known inactivation of pyruvate kinase by glucagon (Engström, 1978) would favour the return of labelled triose phosphates to glucose and thus increase randomization. The complexity of this system therefore prevents a simple conclusion to be drawn.

\section{Regulation of the activity of phosphofructokinase}

Since this activity appears to play a major role in the control of the fructose 6-phosphate/fructose 1,6-bisphosphate cycle, it is of interest to identify the factors responsible for the remarkable difference in its activity in the livers of fed and starved rats as well as after glucagon treatment. The activity of phosphofructokinase is indeed influenced by several effectors (see Hofmann, 1976).

Fructose 6-phosphate. The saturation curve for fructose 6-phosphate is sigmoidal, so that any change in substrate concentration will greatly affect the enzyme activity. Accordingly, the hexose 6phosphate concentration is low in starvation and is increased by the administration of glucose. The fact that a high concentration was reached on administration of both glucose and glucagon to starved rats when recycling was minimal indicates that factors other than substrate concentration play a major role in the control of phosphofructokinase activity.

Fructose 1,6-bisphosphate. This metabolite, the product of the reaction, is a well-known stimulator which will amplify the action of other positive effectors. As shown in Table 2, the concentration of fructose 1,6-bisphosphate was remarkably low in all conditions in which recycling was almost nonexistent. Our data do not allow us to say whether this low concentration of fructose 1,6-bisphosphate is the cause or the result of the low activity of phosphofructokinase.

Nucleotides. ATP, which is a substrate of the 
reaction, is known as an inhibitor of phosphofructokinase, whereas AMP is a stimulator. It is apparent from Table 2 that variations in the concentration of these two nucleotides should cause changes in activity of phosphofructokinase which are the opposite of what was actually observed.

Change in the kinetic properties of phosphofructokinase. The data of Table 3 indicate that both glucagon treatment and starvation decreased the activity of phosphofructokinase when measured at low substrate concentrations. This observation would be in agreement with the hypothesis that the enzyme has been converted into a less-active form characterized by a lower affinity for fructose 6-phosphate (Castaño et al., 1979; Kagimoto \& Uyeda, 1979; Pilkis et al., 1979; Nieto \& Castaño, 1980). As suggested by these authors, this change in activity may result from covalent modification of the protein, for example by phosphorylation catalysed by the cyclic AMP-dependent protein kinase; another interpretation could be that changes in the concentration of a ligand, possibly fructose 1,6-bisphosphate, tightly bound to the enzyme may be responsible for the observed inactivation.

An increase in $V_{\max }$ of phosphofructokinase by glucose and re-feeding has been observed by Brand \& Söling (1975) and by Brand et al. (1976), and these changes in activity were interpreted in terms of phosphorylation of the enzyme by a specific protein kinase.

\section{Is fructose bisphosphatase regulated?}

The concentration of fructose 1,6-bisphosphate in livers of starved rats was one-sixth of that in fed rats, yet gluconeogenesis is known to be faster in the former condition. It therefore follows that fructose bisphosphatase activity is controlled by factors other than substrate concentration. Fructose bisphosphatase has been described as being phosphorylated (Riou et al., 1977), but to date there is no convincing evidence for a change in activity. It is of interest to recall that purified hexose bisphosphatase inactivates purified phosphofructokinase (see Hofmann, 1976) and that this effect has been explained by the removal of the activator fructose 1,6-bisphosphate (Söling et al., 1977).

\section{Comparison with other work}

Because of the presence of transaldolase, which exchanges the lower half of fructose 6-phosphate with triose phosphates without participation of phosphofructokinase (Hue \& Hers, 1974), the attempts made to measure the fructose 6-phosphate/ fructose bisphosphate cycle in the liver by the release of ${ }^{3} \mathrm{H}_{2} \mathrm{O}$ from $\left[5-{ }^{3} \mathrm{H}\right]$ glucose may give false positive results. All conclusions based on this methodology require to be reconsidered (for reviews, see Katz \& Rognstad, 1976; Hue 1980). The use of $\left[3-{ }^{3} \mathrm{H}\right]-$ glucose is not subject to the same criticism, and several groups of investigators (Hue \& Hers, 1974; Katz et al., 1976; Dunn et al., 1976) came to the conclusion that the loss of ${ }^{3} \mathrm{H}_{2} \mathrm{O}$ from this precursor was the same as from $\left[6-{ }^{3} \mathrm{H}\right]$ glucose, and therefore was entirely accounted for by the participation of the Cori cycle even in the fed state. This negative result concerning the existence of a fructose 6-phosphate/ fructose bisphosphate cycle in the liver of fed animals is therefore in contradiction with the data in the present paper. However, as pointed out by Katz \& Rognstad (1976), the methodology based on ${ }^{3} \mathrm{H}_{2} \mathrm{O}$ release may not be sensitive enough to detect a recycling, which may be small in comparison with the Cori cycle; this methology also appears not to be entirely specific. In other work (Chenoweth \& Dunn, 1978; Dunn \& Chenoweth, 1979), based on the use of $\left[3-{ }^{3} \mathrm{H}, 6-{ }^{14} \mathrm{C}\right]$ glucose, the randomization of carbon between the lower and upper halves of glucose over a $90 \mathrm{~min}$ period was taken as a measure of the Cori cycle. Since this randomization also reflects the fructose 6-phosphate/fructose bisphosphate cycle, that work is difficult to interpret.

\section{Note Added in Proof (Received 27 August 1980)}

The second interpretation proposed for the effect of glucagon to change the kinetic properties of phosphofructokinase has been confirmed, and the ligand has been tentatively identified as fructose 2,6-bisphosphate (Van Schaftingen et al., 1980).

This work was supported by the Belgian Fonds de la Recherche Scientifique Médicale and by the U.S. Public Health Service (Grant AM 9235). E. V. S. is Aspirant and L. H. is Chercheur Qualifié of the Fonds National de la Recherche Scientifique.

\section{References}

Adam, H. (1963) in Methods of Enzymatic Analysis (Bergmeyer, H. U., ed.), pp. 573-577, Academic Press, New York and London

Beaufay, H. \& de Duve, C. (1954) Bull. Soc. Chim. Biol. 36, 1525-1537

Bloom, B. (1962) Anal. Biochem. 3, 85-87

Brand, I. A. \& Söling, H. D. (1975) FEBS Lett. 57, 163-168

Brand, I. A., Müller, M. K., Unger, C. \& Söling, H. D. (1976) FEBS Lett. 68, 271-274

Bücher, T. \& Hohorst, H.-J. (1963) in Methods of Enzymatic Analysis (Bergmeyer, H. U., ed.), pp. 246-252, Academic Press, New York and London

Castaño, J. G., Nieto, A. \& Felíu, J. E. (1979) J. Biol. Chem. 254, 5576-5579

Chenoweth, M. \& Dunn, A. (1978) Am. J. Physiol. 235, E295-E303

Dunn, A. \& Chenoweth, M. (1979) Am. J. Physiol. 236, E410-E415

Dunn, A., Katz, J., Golden, S. \& Chenoweth, M. (1976) Am. J. Physiol. 230, 534-535

Engström, L. (1978) Curr. Top. Cell. Regul. 13, 29-51 
Emerk, K. \& Frieden, C. (1975) Arch. Biochem. Biophys. 168, 210-218

Hers, H. G. (1955) J. Biol. Chem. 214, 373-381

Hers, H. G. (1964) Adv. Metab. Disord. 1, 4-44

Hofmann, E. (1976) Rev. Physiol. Biochem. Pharmacol. $75,1-68$

Hohorst, H.-J. (1963) in Methods of Enzymatic Analysis (Bergmeyer, H. U., ed.), pp. 134-138, Academic Press, New York and London

Hue, L. (1980) Adv. Enzymol. in the press

Hue, L. \& Hers, H. G. (1974) Biochem. Biophys. Res. Commun. 58, 532-539

Huggett, A. St. G. \& Nixon, D. A. (1957) Biochem. J. 66, $12 \mathrm{P}$

Kagimoto, T. \& Uyeda, K. (1979) J. Biol. Chem. 254, 5584-5587

Kamath, S. A. \& Rubin, E. (1972) Biochem. Biophys. Res. Commun. 49, 52-59

Katz, J. \& Rognstad, R. (1976) Curr. Top. Cell. Regul. $10,237-289$

Katz, J., Golden, S., Dunn, A. \& Chenoweth, M. (1976) Hoppe-Seyler's Z. Physiol. Chem. 357, 1387-1394

Lamprecht, W. \& Trautschold, I. (1963) in Methods of Enzymatic Analysis (Bergmeyer, H. U., ed.), pp. 543-551, Academic Press, New York and London
Landau, B. R. \& Merlevede, W. (1963) J. Biol. Chem. 238, $861-867$

Nieto, A. \& Castaño, J. G. (1980) Biochem. J. 186, 953-957

Pilkis, S., Schlumpf, J., Pilkis, J. \& Claus, T. H. (1979) Biochem. Biophys. Res. Commun. 88, 960-967

Rauschenbach, P. \& Lamprecht, W. (1964) HoppeSeyler's Z. Physiol. Chem. 339, 277-292

Riou, J. P., Claus, T. H., Flockhart, D. A., Corbin, J. D. \& Pilkis, S. J. (1977) Proc. Natl. Acad. Sci. U.S.A. 74, 4615-4619

Rognstad, R. \& Katz, J. (1976) Arch. Biochem. Biophys. 177, 337-345

Söling, H. D., Bernhard, G., Kuhn, A. \& Lück, H.-J. (1977) Arch. Biochem. Biophys. 182, 563-572

Underwood, A. H. \& Newsholme, E. A. (1965) Biochem. J. 95, 868-875

Van Schaftingen, E., Hue, L. \& Hers, H. G. (1980) Biochem.J. in the press

Weichselbaum, T. E. \& Somogyi, M. (1941) J. Biol. Chem. 140, 5-20

Williams, H. R. \& Landau, B. R. (1972) Arch. Biochem. Biophys. 150, 708-713

Wollenberger, A., Ristau, O. \& Schoffa, G. (1960) Pflügers Arch. Gesamte Physiol. Menschen Tiere 270, 399-412 